\title{
Integration of production as a way to improve the financial stability of non-ferrous metallurgy enterprises in the Far Eastern region of Russia
}

\author{
Yuliya Arkhipova ${ }^{1 *}$ \\ ${ }^{1}$ Mining Institute of Far eastern branch of Russian Academy of Sciences, Khabarovsk, Russia.
}

\begin{abstract}
Article is devoted to a question of financial and economic stability of the enterprises. Uncertainty and instability of the external environment can lead to a slowdown in economic growth, to a decline in production and reduction of investment. In recent years, problems of financial instability and bankruptcy have grown into a category of economic security of the country. Annually for these reasons, thousands of businesses cease operations, which has a negative impact on the social and economic situation of the regions. The article examines the theoretical and methodological tools of financial stability of economic entities as an indicator of the effectiveness of the financial management system in commercial organizations. This is ensured by permanent solvency by maintaining a sufficient level of liquidity of assets (finished goods, receivables, short-term financial investments, etc.). The author made attempts to create a methodology for assessing the financial and economic sustainability of mining companies in the Far Eastern region that are engaged in the extraction and processing of non-ferrous metal ores in order to avoid their bankruptcy and as an exit - merger into a vertically integrated company. This will allow to connect the technological cycle at individual enterprises: from the extraction of raw materials and its processing to the production of high-value products and to increase their competitiveness both on the Russian market and on the world market.
\end{abstract}

\section{Introduction}

Over the ten-year period in non-ferrous metallurgy there are such processes as concentration, integration and diversification. The active formation of holding structures is continuing, they control a significant part of nonferrous metallurgy and are major producers and exporters of metals [1]. The resulting horizontal and vertical integration has united both a multitude of domestic metallurgical enterprises and their suppliers of raw materials and fuel. Except all pluses and minuses of this phenomenon, it has defined independence of the enterprises of metallurgical branch in relation to the global oligopolistic companies, which control the international market of resources, and respectively own instruments of influence

\footnotetext{
${ }^{*}$ Corresponding author: arhipova@igd.knv.ru
} 
on the general price policy, for example, BHB Billiton, CVRD and Rio Tinto which produce $35 \%$ of iron ore raw materials in the world $[2,3]$.

The optimal provision of resources in the holding means satisfying the own needs of the enterprises entering into it, the availability of technological stocks of raw materials and fuel. A particularly significant process is integration in the production of nonferrous metals. According to 2014 - 2015 years, more than $92 \%$ of the proceeds of nonferrous metallurgy are generated by four enterprises: Norilsk Nickel, RusAl, SUAL and UGMC. The analysis of international experience has shown that in nonferrous metallurgy integration by the vertical technological principle is most effective. It allows to connect together a production cycle at the separate enterprises: from extraction of raw materials and its processing and to increase their competitiveness to production of advanced processing in the international markets. In a vertically integrated company, efficiency is achieved by reducing the throughput unit costs for the production of final products (usually in the formation of structures that combine the enterprises from the extraction of raw materials to the production of the third and fourth redistribution) and saving costs associated with the use of third-party contractors and intermediaries. There is a decrease in transaction costs (management costs, loss from adaptation, the cost of finding an advantageous partner, etc.) and reducing the indirect taxation of intermediate products, hence the cost of the final product is usually lower than that of independent competitors that are forced to buy raw materials from the supplier always at affordable prices. Therefore, consolidation in a single vertically integrated structure neutralizes the dependence of metallurgists on suppliers of nonferrous metals concentrates.

Vertical integration (inter-regional) in the mineral sector with the participation of the Far East was particularly evident in nonferrous metallurgy, where for many decades only primary redistribution (extraction and enrichment) of raw materials was developed, and the main products were ores and concentrates. This was especially significant in the tin industry: practically all the stocks of Russian tin are concentrated in the Far East (Yakutia, Khabarovsk and Primorsky Krai, the Jewish Autonomous Region), and practically the only refining enterprise in Russia - the Novosibirsk Tin Plant - is located far beyond the region. The Far Eastern tin-mining enterprises and the combine were units of a single technological chain within the framework of a centrally managed unified national economic complex.

\section{Materials and methods}

Currently, the financial and economic analysis at the metallurgical enterprises is mainly on the study of production and financial reporting, which concludes with an assessment of the risk of bankruptcy. However, the results obtained are often used only informatively in connection with the insufficient elaboration of the algorithms for further management actions. This fact does not allow the maximum use of the information received and deprives many interested persons of the opportunity to manage this type of risk. Risk management will allow the enterprise not only to avoid the state of bankruptcy, but at the same time to increase its competitiveness, investment attractiveness and solvency. The enterprise can effectively develop when it gets net profit which can be reinvested then in development of capacities and the general potential.

Enterprises with the highest risk of bankruptcy can hope only for the help of state authorities, since there is no way for them to fulfill their obligations in any way. Reducing the risk of bankruptcy shows an improvement in the financial condition and the ability to pay off on its obligations with its assets.

Thus, the analysis of the financial and economic situation is the most important aspect and one of the effective ways to assess the current situation. It reflects the instantaneous state of the economic situation and allows you to highlight the most difficult problems of 
managing available resources and minimize efforts to align the organization's goals and resources with the needs and capabilities of the established market. Analysis of the financial condition is a tool for identifying management problems, it is the choice of the directions of investing capital and forecasting individual indicators, and therefore one can make effective decisions in various areas of the economic activity of the enterprise.

In Russian practice, the analysis of "business activity" is the most popular. This concept in financial activity is defined as the whole range of activities that are aimed at promoting these enterprises in all areas: the sales market, financial activities, the labor market, etc. The increase in business activity is manifested in the expansion of the service sector or the sales market, the increase in the range of goods and services and its successful implementation, the stable development of the staff of the enterprise, the efficiency of the use of the entire resource base (finance, personnel, raw materials). The levels and dynamic of certain "financial coefficients" are analyzed, and are indicators of the achieved results in the activities of the enterprise.

Previous studies [4, 5, etc.] suggest that to date, a variety of methods and techniques have been developed to assess financial sustainability. They are both generally accepted and authoritative, based on the consideration of this economic category as a multidimensional phenomenon. Its take into account different aspects, in particular by assessing the impact on domestic financial stability (liquidity of assets and solvency, capital structure and liabilities, cash flow uniformity, tax costs) and external factors (inflation, exchange rate changes, etc.).

\section{Results and discussion}

On the example of the selected mining companies of the Far Eastern region, engaged in mining and processing of nonferrous metal ores, an analysis of their stability was carried out. Were studied financial-economic and accounting statements for the three-year period (2012-2014) of the following enterprises: JSC Dalpolymetall MMC, LLC Pravoormyskoe, JSC Tin Ore Company (JSC ORK), PJSC Rusolovo. Were calculated absolute and relative indicators. The most significant coefficients were identified from the set of existing ones (absolute liquidity, fast, current, total solvency, turnover of capital, working capital, turnover of accounts receivable and accounts payable, etc.), which, in the opinion of the author, more fully characterize the financial situation from the point of view of bankruptcy diagnostics. At the same time, the analysis was carried out in such a manner that the solvency indices were first considered, then - "business activity" and then, according to method the A.A. Trifilova [6] determined financial stability. So, for example, if absolute financial stability is determined for PJSC Rusolovo, then individual solvency ratios and "business activity" reflect unfavorable data [7].

Activity of the companies is profitable (net profit) on all analyzed interval except for 2013 of JSC Dalpolimetall MMC when the loss in the sum of 5.5 million rubles has been received. At the same time, it is not typical for the organization to maintain stable growth rates of the main financial indicators, both in general and for other enterprises, for which negative trends are noted and negative indicators are observed.

Due to the ambiguity of results, we will continue researches at the micro level. Each enterprise demands individual approach to carrying out the analysis of a financial state. The determining factor of the specificity of the activity is the branch belonging of the analyzed object. It was suggested that the use of a multilevel (structured) approach would allow not only to obtain an analytical assessment of the financial state of the economic entity's activity in a specific time interval, but also to compare the performance of business activities with the indicators of the mining industry (DPI) and of the Russian Federation as a whole. Deviations in values and competitive advantages with similar leaders in the field 
were identified. Comparative analysis of financial and economic performance indicators of enterprises taking into account the aspect of hierarchical structuring of the economy will allow to formulate conclusions about the development trends of enterprises as a link of the type of economic activity - DPI in the Russian Federation (RF). Table 1 compares the indicators with the performance of small (including micro) and medium-sized enterprises in general for the Russian Federation, and data on enterprises in the field of mining industry. This will allow performing complex monitoring and control of the financial condition of the enterprise and monitoring negative changes in key economic parameters from the perspective of continuing operations in the future. The analysis was carried out by three companies: LLC Pravoormyskoe, JSC ORK and PJSC Rusolovo. They have the status of small and medium enterprises. JSC Dalpolimetall MMC does not participate in this analysis, since it belongs to the category of large ones.

Investigated enterprises are active participants in the market of marketable products in the sphere of DPI, but economic data indicate a small share of their importance. Let's consider the results of each of them.

LLC Pravoormyskoe. The bulk of the indicators are in an unfavorable range, comparing them with the indicators of the RF and of the DPI. The exception is the profitability of products, which is more than 5 times higher than the indicator of the Russian Federation and 2.3 times of the DPI. Return on capital and reserves is the most important factor in assessing the financial condition of an enterprise and the level of investment attractiveness, and also demonstrates inefficient use of own funds. The coefficient of autonomy shows how the organization is independent of creditors. The smaller the value, the more the organization is dependent on borrowed sources, the less stable the situation. It is $2.5 \%$ with a value of $17 \%$ for the industry DPI. The enterprise has too little opportunity to extinguish debts at its own expense.

$J S C O R K$. The only positive thing is the excess of the current liquidity ratio in comparison with industry-wide, other indicators show low values. A similar situation exists in the PJSC "Rusolovo".

Since none of the analyzed enterprises have absolute stability and some of them are in the risk zone, the next step is to evaluate the effectiveness of the creation of a vertically integrated company (VIC) that unites these economic entities. In this case, we include in the calculations of JSC Dalpolimetall MMC due to unfavorable economic data [7]. The effect of the integration results was evaluated from the point of view of maximizing profit and growth in the capitalization of the association, providing an increase in the business value, as well as an increase in the selected VIC financial indicators after the merger of enterprises compared to the sum of these indicators before consolidation (tab. 2). Estimated data showed that the indicators of the possibility (impossibility) of breakeven activity and financial stability are in a favorable range, while the company's share is significantly increased in comparison with the data on the DPI in the Russian Federation.

Calculation and the analysis of relative indicators supplements results of holding analytical procedures of the reporting of VIK (tab. 3).

Usually high growth rates of accounts receivable testify that the enterprise actively uses the strategy of commodity loans for consumers of its products. By crediting them, the enterprise actually shares with them a part of its income. When payments are delayed, the enterprise is forced to take loans to ensure its economic activities, increasing its own accounts payable. In this case, the ratio of receivables shows a decrease, which is a favorable factor. Also decrease in growth rate of accounts payable is observed that reduces risk of insolvency. Coefficient of restoration of solvency more than 1, i.e. the company in the short term will be able to restore solvency, and the coefficient of loss of solvency (more than 1) confirms it. 


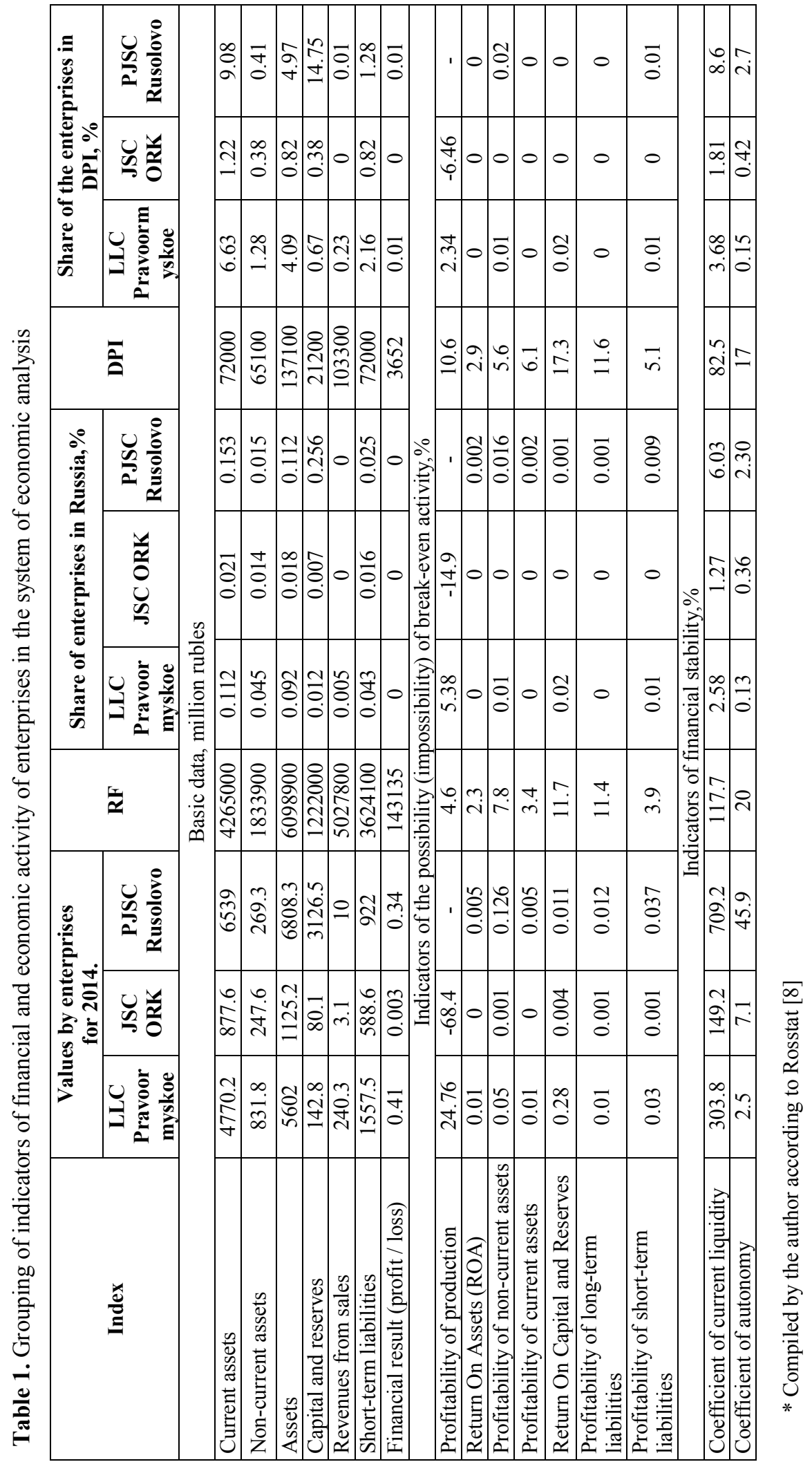


Table 2. Indicators of financial and economic activities of a vertically integrated company

\begin{tabular}{|l|c|c|c|c|c|c|c|c|}
\hline \multicolumn{1}{|c|}{ Index } & $\begin{array}{c}\text { The } \\
\text { value of } \\
\text { the VIC } \\
\text { indicator }\end{array}$ & RF & $\begin{array}{c}\text { Share } \\
\text { of the } \\
\text { VIC, } \\
\text { \% }\end{array}$ & $\begin{array}{c}\text { Deviation } \\
\text { from the } \\
\text { RF data }\end{array}$ & $\begin{array}{c}\text { According } \\
\text { to the RF } \\
\text { DPI }\end{array}$ & $\begin{array}{c}\text { Share } \\
\text { of the } \\
\text { VIC, } \\
\text { \% }\end{array}$ & $\begin{array}{c}\text { Deviation } \\
\text { DPI } \\
\text { from the } \\
\text { RF data }\end{array}$ \\
\hline \multicolumn{7}{|c|}{ Basic data, million rubles } \\
\hline Current assets & 17602.2 & 4265000 & 0.413 & 4247397.8 & 72000 & 24.45 & 54397.8 \\
\hline Non-current assets & 3157.1 & 1833900 & 0.172 & 1830742.9 & 65100 & 4.85 & 61942.9 \\
\hline Assets & 20759.3 & 6098900 & 0.34 & 6078140.7 & 137100 & 15.14 & 116340.7 \\
\hline Capital and reserves & 3435.8 & 1222000 & 0.281 & 1218564.2 & 21200 & 16.21 & 17764.2 \\
\hline Revenues from sales & 2075.3 & 5027800 & 0.041 & 5025724.6 & 103300 & 2.01 & 101224.6 \\
\hline Short-term liabilities & 5118.9 & 3624100 & 0.141 & 3618981.1 & 72000 & 7.11 & 66881.1 \\
\hline $\begin{array}{l}\text { Financial result (profit / } \\
\text { loss) }\end{array}$ & 990.5 & 143135 & 0.692 & 142144.5 & 3652 & 27.12 & 2661.5 \\
\hline \multicolumn{7}{|c|}{ Indicators of the possibility (impossibility) of break-even activity,\% } & \\
\hline $\begin{array}{l}\text { Profitability of } \\
\text { production }\end{array}$ & 15.28 & 4.6 & 3.32 & -10.68 & 10.6 & 1.44 & -4.68 \\
\hline $\begin{array}{l}\text { Return On Assets } \\
\text { ROA) }\end{array}$ & 4.77 & 2.3 & 2.07 & -2.47 & 2.9 & 1.65 & -1.87 \\
\hline $\begin{array}{l}\text { Profitability of non- } \\
\text { current assets }\end{array}$ & 31.37 & 7.8 & 4.02 & -23.57 & 5.6 & 5.6 & -25.77 \\
\hline $\begin{array}{l}\text { Profitability of current } \\
\text { assets }\end{array}$ & 5.63 & 3.4 & 1.66 & -2.23 & 6.1 & 0.92 & 0.47 \\
\hline $\begin{array}{l}\text { Return On Capital and } \\
\text { Reserves }\end{array}$ & 28.83 & 11.7 & 2.46 & -17.13 & 17.3 & 1.67 & -11.53 \\
\hline $\begin{array}{l}\text { Profitability of long- } \\
\text { term liabilities }\end{array}$ & 8.12 & 11.4 & 0.71 & 3.28 & 11.6 & 0.7 & 3.48 \\
\hline $\begin{array}{l}\text { Profitability of short- } \\
\text { term liabilities }\end{array}$ & 19.35 & 3.9 & 4.96 & -15.45 & 5.1 & 3.79 & -14.25 \\
\hline $\begin{array}{l}\text { Indicators of financial stability,\% } \\
\text { liquidity }\end{array}$ & 343.69 & 117.7 & 2.92 & -225.99 & 82.5 & 4.17 & -261.19 \\
\hline Coefficient of autonomy & 16.55 & 20 & 0.83 & 3.45 & 17 & 0.97 & 0.45 \\
\hline
\end{tabular}

* Compiled by the author according to Rosstat [8]

Table 3. Analysis of satisfactory (unsatisfactory) structure of balance of VIK

\begin{tabular}{|l|c|c|c|c|c|c|c|}
\hline \multirow{2}{*}{ Index } & \multicolumn{3}{c}{$\begin{array}{c}\text { Value } \\
\text { indicator }\end{array}$} & \multicolumn{2}{c|}{ Deviation, +/- } & \multicolumn{2}{c|}{$\begin{array}{c}\text { Growth } \\
\text { rate, \% }\end{array}$} \\
\cline { 2 - 9 } & $\mathbf{2 0 1 2}$ & $\mathbf{2 0 1 3}$ & $\mathbf{2 0 1 4}$ & $\begin{array}{c}\mathbf{2 0 1 3}- \\
\mathbf{2 0 1 2}\end{array}$ & $\begin{array}{c}\mathbf{2 0 1 4} \\
\mathbf{- 2 0 1 3}\end{array}$ & $\begin{array}{c}\mathbf{2 0 1 3} \\
\mathbf{2 0 1 2}\end{array}$ & $\begin{array}{c}\mathbf{2 0 1 4} \\
\mathbf{2 0 1 3}\end{array}$ \\
\hline Ratio of changes in receivables, units. & - & 1.9 & 1.31 & - & -0.59 & - & 0.69 \\
\hline Ratio of changes in accounts payable, units. & - & 2.88 & 0.88 & - & -2 & - & 0.3 \\
\hline Current liquidity ratio at the end of the year & 7.97 & 4.37 & 3.44 & -3.6 & -0.93 & 0.55 & 0.79 \\
\hline Coefficient of restoration of solvency & - & 2.57 & 2.97 & - & 0.4 & - & 1.16 \\
\hline Coefficient of loss of solvency & - & 3.47 & 2.33 & - & -1.14 & - & 0.67 \\
\hline
\end{tabular}

The next step in the study is to assess the risk of bankruptcy. To do this, we use the logit model of the author [9], which was developed specifically for metallurgical 
enterprises. The logistic model for "large" enterprises includes 6 indicators, which were previously calculated: the coefficient of long-term borrowing $\left(\mathrm{K}_{2}\right)-0.78$; return on assets $\left(\mathrm{K}_{5}\right)-0.15$; total profitability $\left(\mathrm{K}_{4}\right)-0.57$; net profit rate $\left(\mathrm{K}_{6}\right)-0.48$; the autonomy ratio $\left(\mathrm{K}_{1}\right)$ is 0.17 ; the ratio of debt to equity $\left(\mathrm{K}_{3}\right)$ is 5.04 .

The total logistic model has the following appearance:

$Z=-\left(0.37+3.3 * K_{1}-4.7 * K_{2}+0.5 * K_{3}+1.3 * K_{4}-4.23 * K_{5}+0.15 * K_{6}\right)$

where: $Z$ - probability of bankruptcy of the enterprise.

On the scale of bankruptcy risk levels: if $Z$ is in the range from 0 to 0.3 - low risk, from 0.3 to 0.6 - medium level and from 0.6 to 1 - high. In our case, $Z=0.01$, which confirms the low probability of a crisis, and as a result, based on the analysis, we can conclude that the effectiveness of combining these enterprises in the VIC.

\section{Conclusion}

The problem of financial instability and bankruptcy of enterprises in recent years has grown into a category of problems of economic security of the country. Annually on all districts and regions of the Russian Federation for these reasons thousands of commercial structures stop activity that exerts impact on stability of economic and social situation of regions. And therefore strengthening of internal and external control is required. It is necessary to take measures of administrative behavior and control of change of a financial and economic situation in separately taken enterprise. In this paper, attempts are made to create a methodology for assessing the financial and economic sustainability of enterprises in order to avoid their bankruptcy. And as an output - association in vertically-integrated company. The procedure can be used: 1) financial and economic services and internal management system in order to prevent bankruptcy of mining and metallurgical enterprises; 2) executive authorities, Department of Mineral Resources, Federal Tax Service, Federal service of Russia on financial improvement and bankruptcy, departments of the industry; 3) the Russian and foreign investors - for the purpose of assessment of investment attractiveness of the domestic mining and metallurgical enterprises; 4) Russian commercial banks to assess the creditworthiness, solvency and the possibility of bankruptcy of borrowers; 5) rating and consulting agencies - for the preparation of analytical reviews.

\section{References}

1. I.A. Kradenykh. Problems and prospects of complex development and preservation of bowels of the earth: Theses of reports of the II International school of sciences of the academician K.N. Trubetskoy, 342, (2016).

2. Lehamn Brothers. The Iron Age. European Metals \& Mining. Industry Overview, 64, (2008).

3. Yu.A. Arkhipova. Formation of vertically integrated production in the mining and metallurgical industry (on the example of the Far Eastern region of the Russian Federation), (2006).

4. T.V. Baronina, S.A. Karpovskaya. Management of economic systems: online scientific magazine, (2011).

5. A.S. Dadayan, A.A. Gurdzhiyan. Economy and business: theory and practice, 9 , 42-44, (2015).

6. A.A. Trifilova. Innovations, 6, 67 (2003).

7. Yu.A. Arkhipova. Mining Information and Analytical Bulletin, 21, 374, (2016).

8. Small and medium-sized business in Russia, 96, (2015).

9. V.E. Rygin. Bulletin of the SRSTU (NPI), 5, 84, (2013). 